\title{
Physical Exercise Restores the Generation of Newborn Neurons in an Animal Model of Chronic Epilepsy
}

\author{
Fabricio N. Mendonça ${ }^{1}$, Luiz E. C. Santos ${ }^{1}$, Antônio M. Rodrigues ${ }^{1}$, \\ Sérgio Gomes da Silva ${ }^{2,3}$, Ricardo M. Arida ${ }^{4}$, Gilcélio A. da Silveira ${ }^{1}$, Fulvio A. Scorza ${ }^{1,5}$ \\ and Antônio-Carlos G. Almeida ${ }^{1 *}$
}

\begin{abstract}
1 Laboratório de Neurociência Experimental e Computacional, Departamento de Engenharia de Biossistemas, Universidade Federal de São João del-Rei, São João del-Rei, Brazil, ${ }^{2}$ Instituto do Cérebro, Hospital Israelita Albert Einstein, São Paulo, Brazil, ${ }^{3}$ Núcleo de Pesquisas Tecnológicas, Universidade de Mogi das Cruzes, Mogi das Cruzes, Brazil, ${ }^{4}$ Departamento de Fisiologia, Escola Paulista de Medicina, Universidade Federal de São Paulo (UNIFESP), São Paulo, Brazil, ${ }^{5}$ Disciplina de Neurologia Experimental, Escola Paulista de Medicina, Universidade Federal de São Paulo (UNIFESP), São Paulo, Brazil
\end{abstract}

OPEN ACCESS

Edited by:

João O. Malva,

University of Coimbra, Portugal

Reviewed by:

Daniel A. Peterson,

Rosalind Franklin University of

Medicine and Science, USA

José Luis Trejo,

Consejo Superior de Investigaciones Cientificas, Spain

*Correspondence:

Antônio-Carlos G. Almeida acga@ufsj.edu.br

Specialty section:

This article was submitted to

Neurogenesis,

a section of the journal

Frontiers in Neuroscience

Received: 19 October 2016

Accepted: 14 February 2017

Published: 01 March 2017

Citation:

Mendonça FN, Santos LEC

Rodrigues AM, Gomes da Silva S, Arida RM, da Silveira GA, Scorza FA

and Almeida A-CG (2017) Physical

Exercise Restores the Generation of

Newborn Neurons in an Animal Model

of Chronic Epilepsy.

Front. Neurosci. 11:98

doi: 10.3389/fnins.2017.00098
Neurogenesis impairment is associated with the chronic phase of the epilepsy in humans and also observed in animal models. Recent studies with animal models have shown that physical exercise is capable of improving neurogenesis in adult subjects, alleviating cognitive impairment and depression. Here, we show that there is a reduction in the generation of newborn granule cells in the dentate gyrus of adult rats subjected to a chronic model of epilepsy during the postnatal period of brain development. We also show that the physical exercise was capable to restore the number of newborn granule cells in this animals to the level observed in the control group. Notably, a larger number of newborn granule cells exhibiting morphological characteristics indicative of correct targeting into the hippocampal circuitry and the absence of basal dendrite projections was also observed in the epileptic animals subjected to physical exercise compared to the epileptic animals. The results described here could represent a positive interference of the physical exercise on the neurogenesis process in subjects with chronic epilepsy. The results may also help to reinterpret the benefits of the physical exercise in alleviating symptoms of depression and cognitive dysfunction.

Keywords: epilepsy, physical exercise, neurogenesis, ectopic newborn neurons, DCX

\section{INTRODUCTION}

Temporal lobe epilepsy (TLE) is a neurological disorder characterized by the occurrence of spontaneous and recurrent seizures (Fisher et al., 2005; Duncan et al., 2006). Epilepsy has been associated with cognitive dysfunction and depression (Hattiangady and Shetty, 2008). Among the epilepsy-related alterations in brain function are the loss of hippocampal functional inhibition, the reorganization of hippocampal circuitry and neurodegeneration (Hattiangady and Shetty, 2008, 2010). In the last years, abnormal neurogenesis in the dentate gyrus has been one of the main topics of focus in TLE investigations (Parent et al., 1997, 2006; Scharfman et al., 2000, 2002, 2003; Parent and Lowenstein, 2002; Hattiangady et al., 2004; Kuruba et al., 2009; Hattiangady and Shetty, 2010). In animal models of epileptogenesis, the first moments after status epilepticus (SE) (latent phase) are characterized by increased cellular proliferation and pronounced aberrant neurogenesis. However, the chronic phase of the disease is marked by a substantial reduction in neurogenesis (Hattiangady et al., 2004; Walter et al., 2007; Kuruba et al., 2009). 
In addition to the decrease in neurogenesis in the dentate gyrus, the ectopic migration of granule cells (aberrant neurogenesis) has also been observed in brain slices from epileptic patients (Parent et al., 2006) as well as in experimental models of chronic epilepsy (Parent et al., 1997; Scharfman et al., 2000; Dashtipour et al., 2003; Bonde et al., 2006; Jessberger et al., 2007a,b; Walter et al., 2007). It has been proposed that these ectopic granule cells act as "hub cells," receiving a disproportional amount of excitatory input compared with normotopic granule cells and being able to generate intrinsic bursts, trigger seizures and, therefore, play a significant role in epileptogenesis (Scharfman and Pierce, 2012; Hester and Danzer, 2013). An additional abnormality described in experimental models of epilepsy is the occurrence of granule cells with basal dendrites with aberrant projections into the hilus. This phenomenon and the ectopic granule cells have been considered enough to increase excitability due to the formation of recurrent circuits connecting the mossy fibers and the normotopic granule cells of the dentate gyrus (Ribak et al., 2000; Austin and Buckmaster, 2004; Shapiro and Ribak, 2006; Hattiangady and Shetty, 2008; Thind et al., 2008).

In mammals, the subgranular zone of the dentate gyrus is one of the two brain areas where neurogenesis is present throughout life (Gage, 2000; Alvarez-Buylla and Lim, 2004; Duan et al., 2008; Zhao et al., 2008; Ma et al., 2009; Ming and Song, 2011). Evidence has shown that physical exercise can induce hippocampal neurogenesis by increasing the release of neurotrophins, particularly brain-derived neurotrophic factor (BDNF) (Cotman and Berchtold, 2002; Vaynman et al., 2004; Vaynman and Gomez-Pinilla, 2005; Olson et al., 2006). Therefore, physical exercise has been proposed as potential non-invasive complementary therapy promoting health and nervous tissue repair in distinct neurological/neurodegenerative syndromes (Cotman and Berchtold, 2002; Russo-Neustadt et al., 2004; Cotman et al., 2007; van Praag, 2008; Arida et al., 2013; Intlekofer and Cotman, 2013). In the present work, we investigated the effect of physical exercise on the number, location, and morphology of newborn neurons within the dentate gyrus in adult rats subjected to SE during the postnatal period of brain development. Notably, physical exercise was able to restore the generation of newborn neurons to the level observed in the control group. Despite the continued existence of ectopic newborn neurons, an increase on the number of newly generated granule cells exhibiting morphological characteristics indicating normal migration and integration into the hippocampal circuitry were observed in the epileptic rats subjected to the physical exercise.

\section{MATERIALS AND METHODS}

\section{Animals}

All procedures involving animals were approved by the Institutional Animal Care and Use Committee guidelines from the Federal University of São João del-Rei, and all efforts were made to minimize animal suffering and to reduce the number of animals used. Water and food were freely available, and room humidity $\left(21 \pm 2^{\circ} \mathrm{C}\right)$ and temperature $(50 \pm 10 \%)$ were controlled and the animals were housed in a $12: 12 \mathrm{~h}$ light-dark cycle.

\section{Status Epilepticus Induction and Epileptogenesis}

According to Cavalheiro et al. (1987), the maturity of the brain cholinergic neurons is required so that the status epilepticus can trigger the epileptogenic process, which will lead to the development of chronic TLE. Therefore, to attain functionally mature cholinergic neurons (Cavalheiro et al., 1987), 28-dayold male Wistar rats $(N=50)$ were injected with pilocarpine chloride $(320 \mathrm{mg} / \mathrm{kg}$, i.p.) to induce SE. Prior to the pilocarpine injection, rats were injected with methylscopolamine $(1 \mathrm{mg} / \mathrm{kg}$, i.p.) to preclude peripheral damage. After $120 \mathrm{~min}$ of SE, rats were given an injection of diazepam $(10 \mathrm{mg} / \mathrm{kg}$, i.p.) to mitigate seizure activity. The rats that survived SE $(N=16)$ were monitored $24 \mathrm{~h}$ a day by a motion detection system and infrared night illumination from day 45 to postnatal day 59, with all the animals having at least two spontaneous seizures (with a minimum interval of $24 \mathrm{~h}$ between seizures) since the last day of monitoring. The following groups of rats were formed after 30 days of SE: SErats solely subjected to $\mathrm{SE}(N=8)$; $\mathrm{SE} / \mathrm{EX}$ - rats subjected to $\mathrm{SE}$ with subsequent physical exercise $(N=8)$ and $\mathrm{C}$-control rats $(N=8)$.

\section{Training Procedure}

Animals in all groups were familiarized with treadmill running and the trainability test using the scale proposed by Dishman et al. (1988). Literature data indicate that 3 days of exercise are able to increase the level of neurotrophins and cell proliferation in the hippocampus (Gómez-Pinilla et al., 1997; van der Borght et al., 2009) and 7 days of running on the treadmill are able to increase the number of young $\mathrm{DCX}^{+}$neurons (Brown et al., 2003; Steiner et al., 2004; Uda et al., 2006; van der Borght et al., 2009). The expression of doublecortin (DCX) occurs in a transient state of neuronal development that lasts for approximately 2 weeks (Kim et al., 2002). In the present study, we chose to use a protocol of physical exercises where the initial phase of increase in both proliferation and generation of newborn neurons were stabilized. Thus, at the end of the physical exercise protocol, the neurons belonging to the proliferation of the first days of physical exercise would already be adults and no longer expressing DCX, however, due to the continuing physical exercise, other newborn neurons will be taking place and the DCX expressing level would be stabilized at an increased but constant level. Then, after the familiarization process, the rats in the SE/EX group were subjected to 28 sessions of treadmill running over the course of 4 weeks ( 1 session/day). A warm-up consisting of running at a speed of $8 \mathrm{~m} / \mathrm{min}$ for $5 \mathrm{~min}$ preceded all exercise sessions. The speed and duration of each session were $10 \mathrm{~m} / \mathrm{min}$ and $10 \mathrm{~min}$, increasing in increments of $2 \mathrm{~m} / \mathrm{min}$ and $5 \mathrm{~min}$ per week to a maximum of $16 \mathrm{~m} / \mathrm{min}$ and $25 \mathrm{~min}$ in the last week. The rats in the other two groups were subjected to all the processes associated with transport to the exercise room and the corresponding manipulation, but were not subjected to the physical exercise session. 


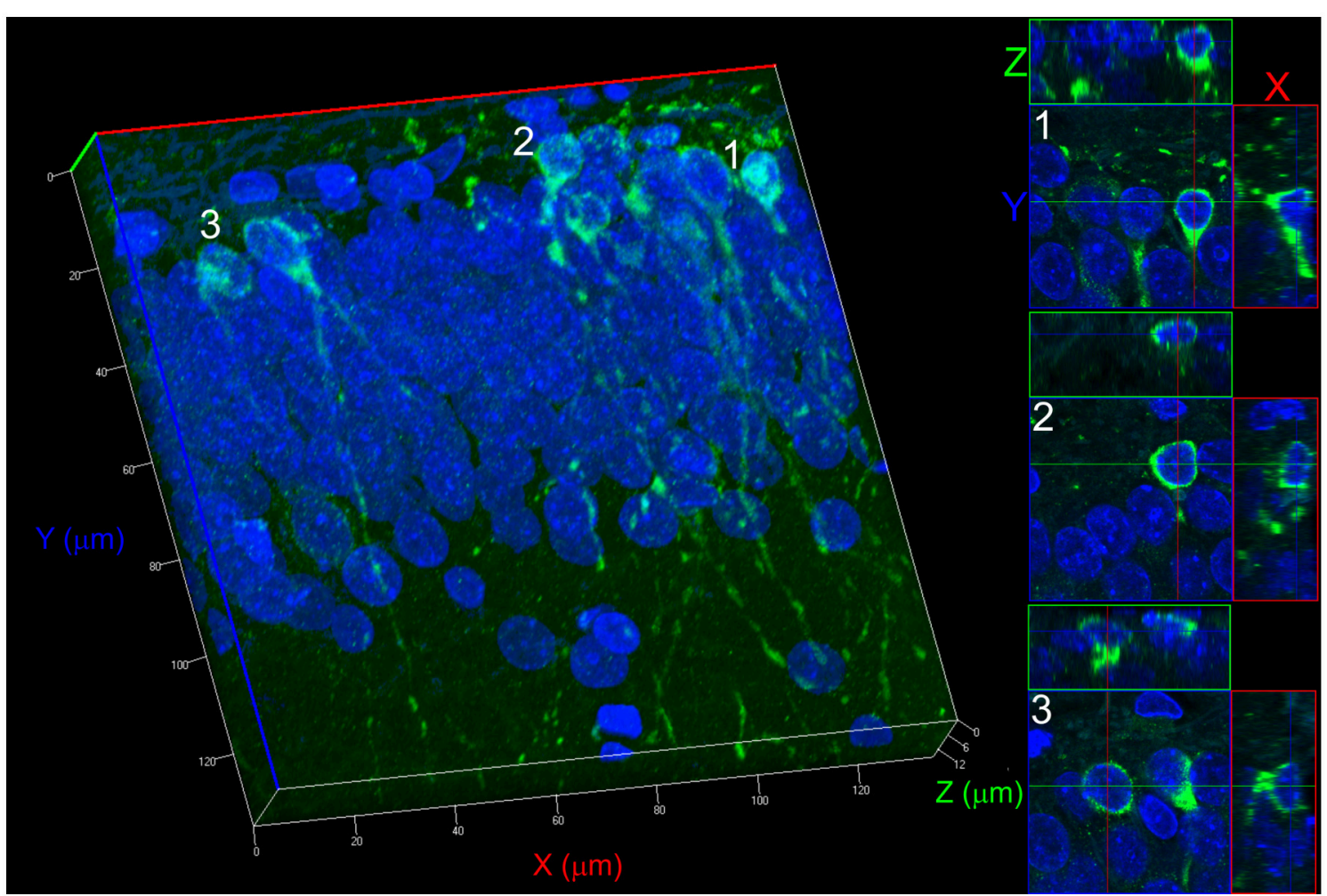

FIGURE 1 | 3D reconstruction process for counting newborn neurons. The example shown refers to a Control group. The reconstruction was performed with 15 confocal z-stacks, $0.8 \mu \mathrm{m}$ increments, pinhole adjusted to 1 Airy unit, with a $63 \times$ oil-immersion objective. The projections on the $\mathrm{X}$, Y, and Z planes allow determining the non-overlapping positioning of two cells from two different confocal optical sections, avoiding a misidentification of morphology type. Three different cell projections $(1,2$, and 3 ) are shown on the right side demonstrating how cells can be seen for identification and counting.

\section{Immunohistochemistry}

At 90 days of age, the rats were anesthetized with an overdose of ketamine-xylazine (100-10 mg/kg, respectively) followed by transcardial perfusion with $0.1 \mathrm{M}$ phosphate-buffered saline (PBS; $\mathrm{pH} 7.4$ ) followed by a $2 \%$ paraformaldehyde (PFA) fixative solution. The brains were dissected, post-fixed in PFA for $24 \mathrm{~h}$, washed, and stored in PBS at $4^{\circ} \mathrm{C}$ until sectioning. Brains were sectioned coronally at a thickness of $40 \mu \mathrm{m}$ with a vibrating microtome (Leica Microsystems, Wetzlar, Germany). The histological sections were preincubated for $90 \mathrm{~min}$ at room temperature in blocking solution (10\% BSA and $0.1 \%$ Triton $\mathrm{X}-100$ ). Overnight incubation in the primary antibody solution containing $2 \%$ BSA was subsequently performed. An anti-DCX antibody (rabbit polyclonal, 1:1,000; Abcam, Cambridge, USA) was used to stain developing immature neurons.

\section{Confocal Microscopy and Histological Analyses}

To assess the number, morphology and location of newborn granule cells, confocal optical sections (COS) of the entire DCXlabeled dentate gyrus were used to count the DCX+ neurons. Imaging was performed using a Zeiss LSM710 confocal system set up on an Observer-Z1 inverted microscope with a $20 \times$ objective (numerical aperture 0.50). All images were captured with identical confocal settings for each animal (excitation wavelength, $488 \mathrm{~nm}$; the same power settings; emission range collected, 493-586 nm). From the captured images (frames) a reconstruction of the entire area of the dentate gyrus was made, creating the image of $6,000 \times 4,000$ pixels (24 megapixels) This image is a COS. Three COS per histological section and 6 histological section per rat were used in the quantification, resulting a total of $18 \mathrm{COS}$ per rat. From each hippocampus 3 sections were taken, one $600 \mu \mathrm{m}$ apart from each other. Three COS images were captured per histological section. The first COS was captured centered at $7 \mu \mathrm{m}$, the next at $19 \mu \mathrm{m}$ and the third at $31 \mu \mathrm{m}$. According to Wojtowicz and Kee (2006), when counting of DCX + cells, due to the small number of cells, usually 80-100 cells per section, a fewer sections per hippocampus are sufficient. The histological sections were obtained in the coronal plane, from rostral to caudal, from the middle portion of the hippocampus, from AP: -2.6 to $-4.6 \mathrm{~mm}$, having the bregma suture as reference, using the Paxinos and Watson (2007) stereotaxic Rat Brain Atlas. Once the middle portion of the hippocampus was determined, the intermediate slice was chosen, identifying the one whose anatomical structures were the closest to those presented in the Atlas at AP: $-3.6 \mathrm{~mm}$. The other two were chosen by taking the nearest slice of $\mathrm{AP}=-3.0 \mathrm{~mm}$ and the nearest slice of $\mathrm{AP}=-4.2 \mathrm{~mm}$. The $\mathrm{DCX}+$ neurons of the 


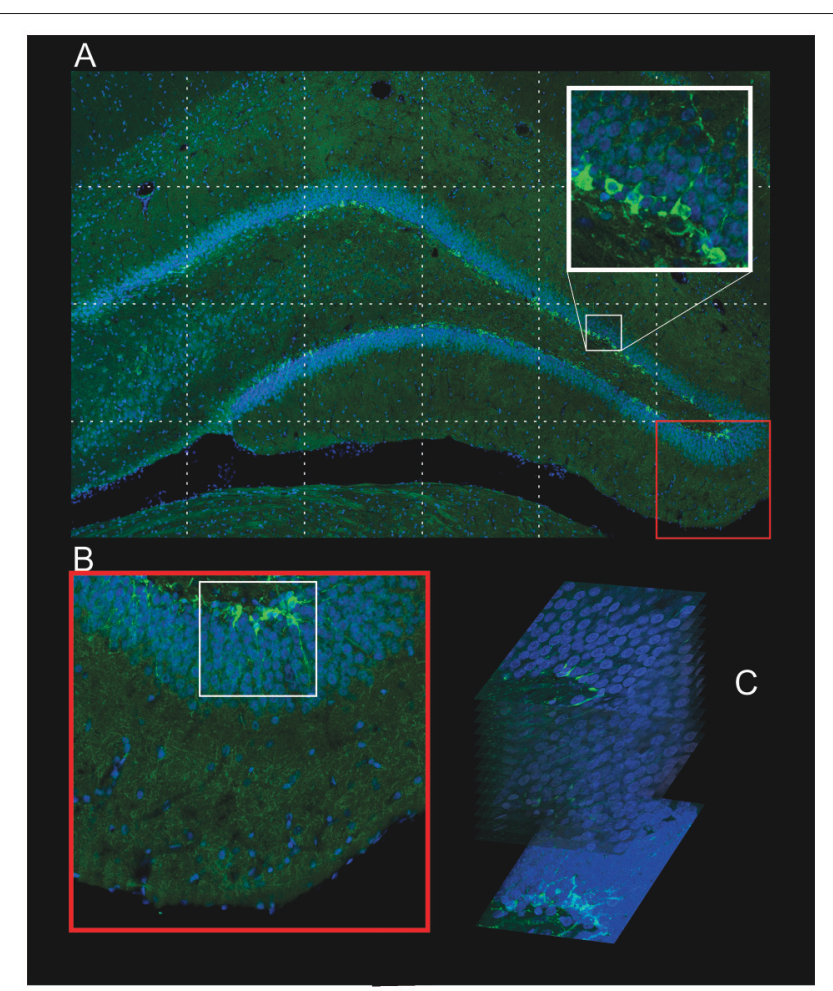

FIGURE 2 | Procedure used in the identification of the newborn neurons. (A) Confocal Optical Section (COS) image of the whole DG in high resolution (24 megapixels) composed with several pictures captured using the $20 \times$ objective. The high-resolution of the COS is enough to identify the morphology of the DCX+ neurons and also to count (red square). (B) The COS image is used to monitor the regions (white square, bottom left) that will be captured with $63 \times$ objective in different z-stacks, 0.8 increments. (C) The summation of these stacks gives the image used to identify the morphology type of the newborn neuron (bottom right).

COS were manually identified, classified and counted using a program developed in Matlab platform. When necessary, using the ZEN 2010b software (Zeiss, Jena, Thuringia, Germany), the morphology and location of the stained neurons were determined using a three-dimensional reconstruction using 15 confocal $\mathrm{z}$ stacks, $0.8 \mu \mathrm{m}$ increments, pinhole adjusted to 1 Airy unit, with a $63 \times$ oil-immersion objective (Figures 1, 2). All cells DCX+ are marked with the "position" function of the ZEN 2010b (Zeiss, Jena, Thuringia, Germany). This function saves the (x,y,z) coordinates. When it is not clear the pertinence of the cell to the optical section, like in the situation of lost caps, or when it is not clear the morphology of the cell, with these coordinates the Software is able to reconstruct the $3 \mathrm{D}$ image (63x objective) centered in the corresponding coordinates.

\section{Statistical Analysis}

We compared control rats with epileptic rats and with epileptic rats subjected to physical exercise. The average number of the different types of DCX+ neurons investigated per COS (n/cos) was the variables analyzed. We used the Shapiro-Wilk normality test to verify the normality of the data. Quantitative variables are reported as mean \pm standard deviation (SD) and were compared using One-way analysis of variance (ANOVA) tests and Tukey's multiple comparison tests when the variable analyzed was compared between more than two groups. When the comparison involved only two groups, it was used Student's $t$-test. A $P<0.05$ was considered as significant.

\section{RESULTS}

The number, location, and morphology of the newborn neurons in the dentate gyrus were assessed in each animal with DCX immunohistochemistry (Brown et al., 2003; Couillard-Despres et al., 2005; Wojtowicz and Kee, 2006). Samples were first analyzed for the presence of cells that showed fluorescent labeling for DCX and these were named DCX+ neurons. As shown in Figure 4A, the SE group exhibited fewer DCX+ neurons than the rats in the $\mathrm{C}$ and SE/EX groups. The average number of DCX+ neurons per COS in the chronic pilocarpinetreated epileptic rats subjected to physical exercise was not significantly different from the number observed in the $\mathrm{C}$ group (DCX+ C: $65.51 \pm 3.94 \mathrm{n} / \mathrm{cos}, \mathrm{SE}: 43.94 \pm 5.21 \mathrm{n} / \mathrm{cos}, \mathrm{SE} / \mathrm{EX}$ : $61.85 \pm 8.40 \mathrm{n} / \mathrm{cos})$.

Next, DCX + neurons were investigated for targeting and classified into two groups. DCX + neurons with the cell body regularly located in the granule layer were classified as normotopic newborn neurons $(\mathrm{nDCX}+)$. DCX + neurons ectopically located in the hilus were classified as abnormal newborn neurons ectopically located in the hilus (ehDCX + ). In Figure 3, the migration targeting of the newborn neurons on the $\mathrm{C}, \mathrm{SE}$ and SE/EX groups are shown. Comparing the groups for the location of the newborn neurons, the average number of $n D C X+(n / c o s)$ was different in the three groups (higher in the group $\mathrm{C}$, followed by SE/EX and lower in the group $\mathrm{SE})(\mathrm{nDCX}+\mathrm{C}: 65.51 \pm 3.94 \mathrm{n} / \mathrm{cos}, \mathrm{SE}: 35.85 \pm 5.429 \mathrm{n} / \mathrm{cos}$, SE/EX: $55.35 \pm 8.35$ n/cos; Figure 4B). There was no statistically significant difference between the groups SE e SE/EX for the variable ehDCX $+($ ehDCX + SE: $8.10 \pm 2.35 \mathrm{n} / \mathrm{cos}$, SE/EX: 6.50 $\pm 2.28 \mathrm{n}$ /cos; Figure 4B).

In the next step, the nDCX + neurons were analyzed for the occurrence of deep basal dendrite in the hilus. $\mathrm{nDCX}+$ neurons with no basal dendritic projecting into the dentate hilus were classified as normotopic regular newborn neurons ( $\mathrm{nrDCX}+$ ). $\mathrm{nDCX}+$ neurons located in the granule layer, but with basal dendrites projecting to the hilus were classified as normotopically located newborn neurons with basal dendrites projecting into the dentate hilus (nbdDCX+). Figure 3B shows a neuron with a basal dendrite. The three-dimensional reconstruction images in Figure 3 were formed from 15 confocal image stacks through the $\mathrm{z}$-depth, allowing identification of the basal dendrites in newborn neurons stained with DCX. There was no statistically significant difference between the SE and SE / EX groups in the variable nbdDCX + (nbdDCX+ SE: $8.61 \pm 1.64$ n/cos, SE/EX: $9.42 \pm 1.93$ $\mathrm{n} / \mathrm{cos}$ ). The average number of nrDCX + neurons per COS in the SE/EX rats was significantly lower than the number in rats from the $\mathrm{C}$ group and greater than the number in the SE rats (Figure 4C; nrDCX+ C: $65.51 \pm 3.94 \mathrm{n} / \mathrm{cos}, \mathrm{SE}: 27.24 \pm 5.32$ n/cos, SE/EX: $47.38 \pm 9.62 \mathrm{n} / \mathrm{cos})$. 


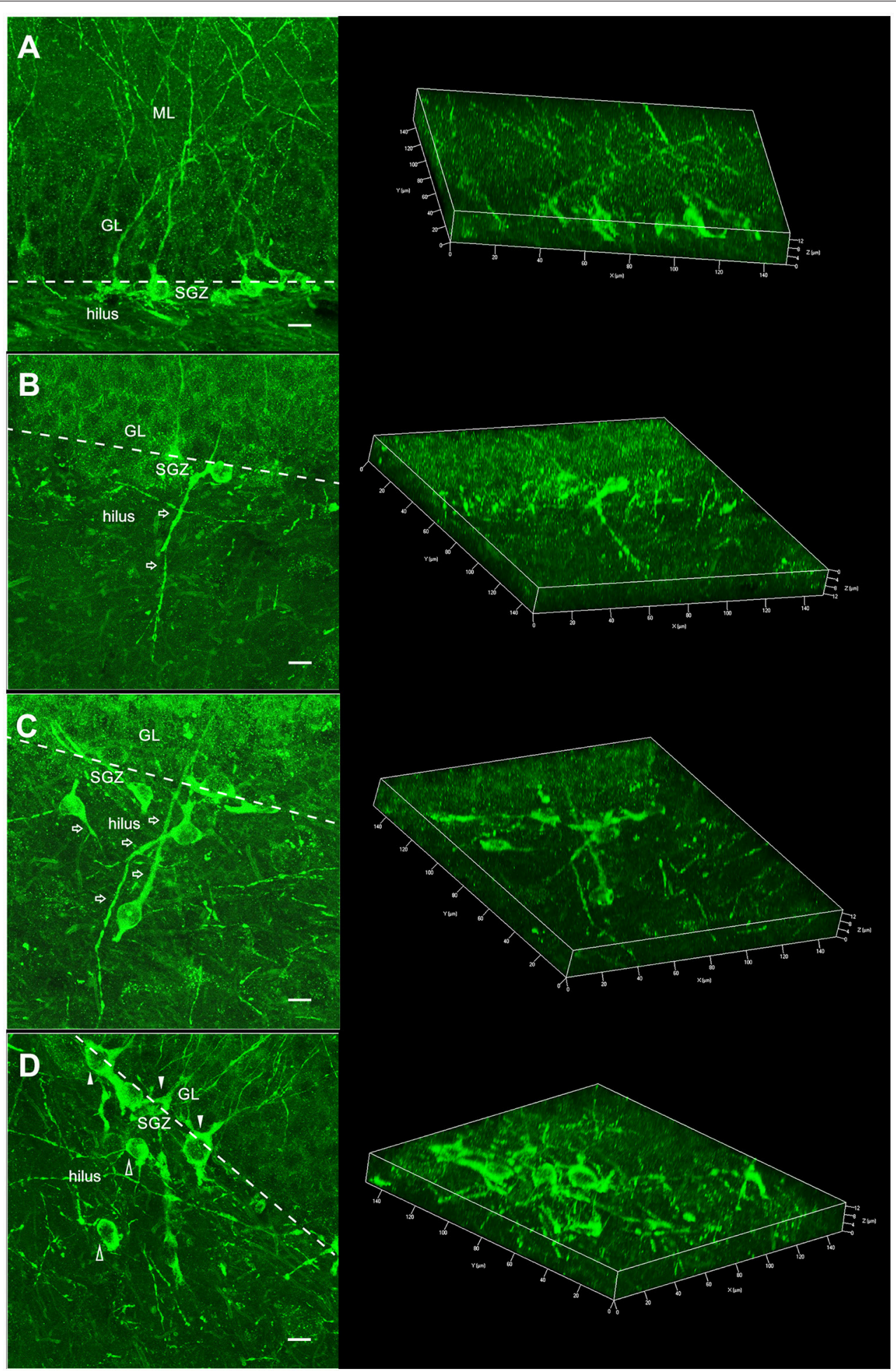

FIGURE 3 | Morphology of the DCX+ neurons showed in two different views: summation of several confocal optical sections allowing to view the complete morphology of the newborn neuronal (left) and 3D reconstruction where the confocal optical sections were rendered and the spatial morphology of the newborn neuronal can be inspected from different visions (right). (A) DCX+ neuron with regular localization and morphology: cell body in the dentate gyrus granule/subgranule layer and apical dendrite toward the $\mathrm{ML}$ /perforant path, typical of the $\mathrm{C}$ group (nrDCX+). (B) $\mathrm{DCX}+$ normotopic neuron with basal dendrites reaching deep into the hilus (nbdDCX+). This morphology was observed in the SE and SE/EX groups. (C) DCX+ ectopic neurons (ehDCX+) localized in the hilus and with aberrant dendrites (open arrows). This characteristic was observed in the SE and SE/EX groups. (D) nrDCX+ neurons (filled arrowheads) and ehDCX+ neurons (open arrowheads) in the same image, a common characteristic observed in the SE/EX group (ML, molecular layer; GL, granule layer; SGZ, subgranule zone; bar, $10 \mu \mathrm{m})$. 
In order to compare the data reported in the literature on abnormal neurons in animal models of chronic epilepsy (Jessberger et al., 2007b; Walter et al., 2007), the ehDCX+ neurons and the nbdDCX + neurons were grouped into a single group termed as abnormal DCX + neurons. Almost half of the DCX + neurons in the SE rats presented abnormalities in localization and/or presence of basal dendrites, $16.70 \pm 3.25$ abnormal $\mathrm{n} / \cos$ out of $43.94 \pm 5.21$ total DCX $+\mathrm{n} / \cos$. In the $\mathrm{SE} / \mathrm{EX}$ group, $15.92 \pm 3.54$ abnormal $\mathrm{n} / \mathrm{cos}$ out $61.85 \pm 8.40$ of total $\mathrm{n} / \mathrm{cos}$ of the DCX+ neurons exhibited abnormalities. However, the number of abnormal DCX+ neurons per COS was not significantly different between the SE and SE/EX groups.

\section{DISCUSSION}

Recent findings have converged on the hypothesis that the abnormal integration of adult-generated newborn dentate granule cells has effect on the development of TLE (Parent and Lowenstein, 2002; Hester and Danzer, 2013; Althaus et al., 2015). It has also been demonstrated that physical exercise promotes adult hippocampal neurogenesis (Cotman and Berchtold, 2002; Fabel et al., 2003; Lee et al., 2013; Nokia et al., 2016). Although decreased neurogenesis is not causally associated with epilepsy and is, in fact, an effect of the disease, it is reasonable to suspect that the beneficial effects of physical exercise on the comorbidities associated with epilepsy (Roth et al., 1994; Gobbo and O'mara, 2005; Arida et al., 2012; Gomes et al., 2014) might be due to changes in the neurogenesis processes (Hattiangady and Shetty, 2008). To test this prediction and evaluate the neuronal changes, we determined the number, location and morphology of the newborn neurons in the dentate gyrus by comparing anti-DCX staining in pilocarpine-treated epileptic rats subjected and not subjected to physical exercise and also control rats.

The present study revealed a significant reduction in the generation of newborn granular cells in epileptic rats compared to control rats. Despite the nonconventional counting protocol used, where the density of DCX + neurons per section were evaluated, and not an estimate of the total number of DCX+ neurons in the hippocampus as usually is performed using stereological sampling, the measure was able to quantify significant changes that were consistently shown in the slices of all animals investigated. The results are in agreement with previous demonstrations of reduced hippocampal neurogenesis in the chronic phase of the disease (Hattiangady et al., 2004; Walter et al., 2007). The disease-induced changes in microenvironment, such as reduced levels of neurotrophic factors (FGF-2, IGF-1, and BDNF), observed in chronic epileptic hippocampi, and the non-neuronal fate-choice decision of newly born cells, are being implicated as the main cause of the reduced neurogenesis (Shetty et al., 2003; Hattiangady et al., 2004; Hattiangady and Shetty, 2008, 2010). The reduction in the generation of newborn granule cells observed in the epileptic group was not observed in the epileptic group subjected to physical exercise. Therefore, besides the cellular proliferation as described in Gomes et al. (2014), the present findings suggest that physical exercise could be able to affect the neuronal
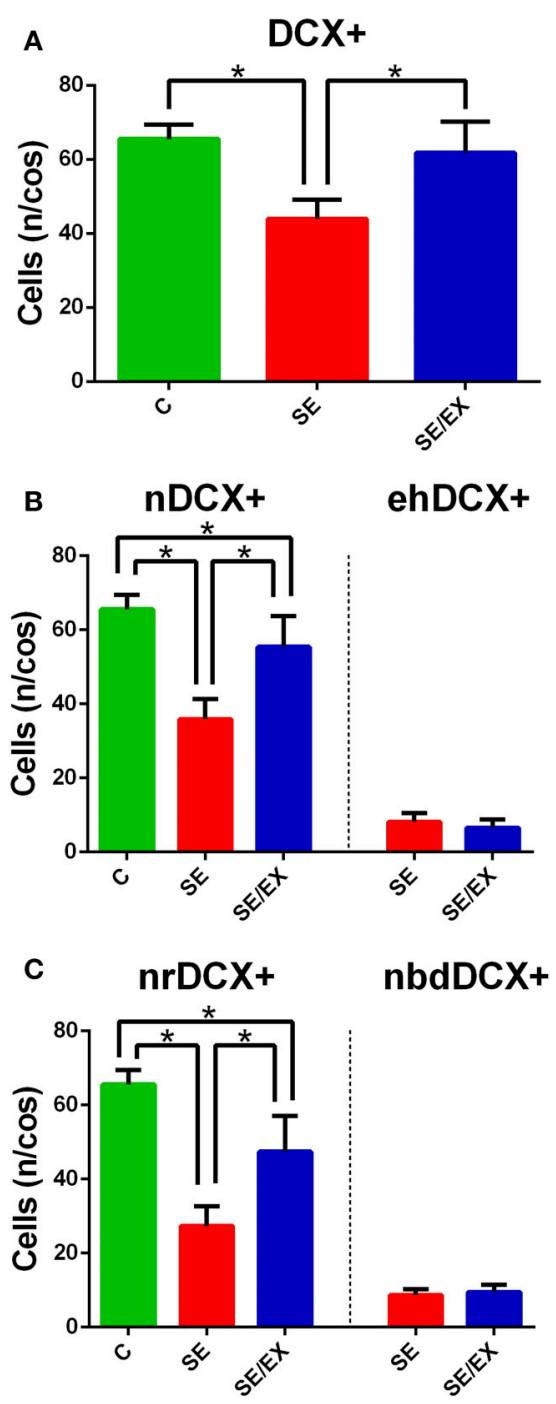

FIGURE 4 | Statistical comparison of the DCX+ stained neurons in the DG for the groups C, SE, and SE/EX groups. (A) The average number of $\mathrm{DCX}+$ stained neurons per confocal optical section is lower in the SE group. (B) The average number of normotopic DCX+ stained neurons is lower in the SE group. There was no statistically significant difference of the average number of ectopic hilar DCX+ stained neurons per confocal optical section between the groups SE and SE/EX. (C) The average number of normotopic regular DCX+ stained neurons per confocal optical section is lower in the group SE. The average number of normotopic neuron with basal dendrites reaching deep into the hilus DCX+ stained neurons was not different comparing SE and SE/EX groups. * $p<0.05$ a One-way ANOVA and Tukey's Post-hoc for DCX+, nDCX+, nrDCX+. ${ }^{*} p<0.05$ a Student's $t$-test for ehDCX+, nbdDCX+. Data are expressed in mean \pm SD.

differentiation of newly born cells in the chronically epileptic hippocampus. The main effect may be a positive contribution to the neurogenesis, counteracting the neurodegeneration associated with epilepsy.

Despite the absence of changes in the number of abnormal newborn neurons observed, the present data show that physical exercise is able to promote an increase in the number of regular 
newborn neurons. Many studies had reported the beneficial effects of physical exercise in decreasing the frequency and severity of seizures (Denio et al., 1989; Eriksen et al., 1994; Arida et al., 1998, 1999, 2003, 2007; McAuley et al., 2001; Gomes et al., 2014). According to Walter et al. (2007), newborn granule neurons may be more vulnerable to environmental disturbances than mature neighboring neurons. Therefore, the initial SE insult as well as the occurrence of spontaneous seizures may affect the migration and maturation processes, leading to both the occurrence of hilar ectopic neurons as well as hilar basal dendrites on the normotopic neurons (Jessberger et al., 2007a,b; Walter et al., 2007). Indeed, taking into account the expected recursive interplay of the effects, the occurrence of fewer seizures may result in fewer abnormalities in the newborn neurons induced by physical exercise.

The positive effects of physical exercise on mood disorders in subjects with epilepsy may be reinterpreted with the present findings. Disruption of the neurogenesis induced by antidepressant drugs blocks the behavioral improvements due to these drugs (Malberg et al., 2000; Manji et al., 2001; Nestler et al., 2002; Santarelli et al., 2003; Drew and Hen, 2007; Sahay and Hen, 2007; David et al., 2009). Once antidepressant drugs induce normal neurogenesis, the beneficial effects of physical exercises in epilepsy, particularly in reducing depression (Roth et al., 1994; Arida et al., 2012; de Lima et al., 2013), may be reinterpreted taking into account the increase in the number of newborn neurons revealed in our data.

Another comorbidity of epilepsy that is positively affected by physical exercise is cognitive impairment (Gobbo and O'mara, 2005; Gomes et al., 2014). Our data may also contribute to the understanding of this effect. According to Cho et al. (2015), the cognitive dysfunction resulting from pilocarpine induced$\mathrm{SE}$ is associated with the neurogenesis of ectopic neurons. This association was also observed in other models of epilepsy (Jessberger et al., 2007a; Scharfman and Pierce, 2012) and the interpretation is that the ectopic neurons may contribute

\section{REFERENCES}

Althaus, A. L., Sagher, O., Parent, J. M., and Murphy, G. G. (2015). Intrinsic neurophysiological properties of hilar ectopic and normotopic dentate granule cells in human temporal lobe epilepsy and a rat model. J. Neurophysiol. 113, 1184-1194. doi: 10.1152/jn.00835.2014

Alvarez-Buylla, A., and Lim, D. A. (2004). For the long run: maintaining germinal niches in the adult brain. Neuron 41, 683-686. doi: 10.1016/S0896-6273(04)00111-4

Arida, R. M., Cavalheiro, E. A., and Scorza, F. A. (2012). From depressive symptoms to depression in people with epilepsy: contribution of physical exercise to improve this picture. Epilepsy Res. 99, 1-13. doi: 10.1016/j.eplepsyres.2011.10.012

Arida, R. M., da Silva Fernandes, M. J., Scorza, F. A., Preti, S. C., and Cavalheiro, E. A. (2003). Physical training does not influence interictal LCMR glu in pilocarpine-treated rats with epilepsy. Physiol. Behav. 79, 789-794. doi: 10.1016/S0031-9384(03)00204-X

Arida, R. M., de Almeida, A. C. G., Cavalheiro, E. A., and Scorza, F. A. (2013). Experimental and clinical findings from physical exercise as complementary therapy for epilepsy. Epilepsy Behav. 26, 273-278. doi: 10.1016/j.yebeh.2012.07.025 to sustaining epileptiform activity (Parent, 2007), thus they may be more crucial to functional alteration following SE than neurogenesis in a brain not injured. Evidences have been collected sustaining the role of the newborn neurons in the DG of the hippocampus improving or maintaining learning and memory functions (van Praag et al., 1999; Shors et al., 2002; van Praag et al., 2002; Drapeau et al., 2003; Cao et al., 2006; Uda et al., 2006). Therefore, although our findings show that physical exercise does not reduce the number of ectopic newborn neurons, the increase in the number of normotopic regular newborn neurons could counteract the effect of the ectopic neurons, which may contribute for reducing cognitive impairment. Further investigations must be conducted to support this hypothesis. Our findings motivate the design of new investigations focused on the survival and functionality of newborn neurons, paving the way to unravel the mechanisms responsible for the beneficial effects of physical exercise on epilepsy comorbidities.

\section{AUTHOR CONTRIBUTIONS}

FM: carried out the experiments, interpreted the data and collaborated in the manuscript writing. LS: performed the confocal microscopy images. AR: analyzed the data and discussed the manuscript writing. SG, RA, GD, and FS: discussed the results and the manuscript writing. A-CA: designed experiments interpreted the data and wrote the manuscript.

\section{ACKNOWLEDGMENTS}

Support to conduct this work was provided by Fapemig (Fundação de Amparo à Pesquisa do Estado de Minas Gerais), CNPq (Conselho Nacional de Desenvolvimento Científico e Tecnológico), FAPESP (Fundação de Amparo à Pesquisa do Estado de São Paulo), INNT (Instituto Nacional de Neurociência Translacional) and CAPES (Coordenação de Aperfeiçoamento de Pessoal de Nível Superior).

Arida, R. M., de Jesus Vieira, A., and Cavalheiro, E. A. (1998). Effect of physical exercise on kindling development. Epilepsy Res. 30, 127-132. doi: 10.1016/S0920-1211(97)00102-2

Arida, R. M., Scorza, C. A., Scorza, F. A., da Silva, S. G., da Graça NaffahMazzacoratti, M., and Cavalheiro, E. A. (2007). Effects of different types of physical exercise on the staining of parvalbumin-positive neurons in the hippocampal formation of rats with epilepsy. Prog. Neuropsychopharmacol. Biol. Psychiatry 4, 814-822. doi: 10.1016/j.pnpbp.2007. 01.021

Arida, R. M., Scorza, F. A., dos Santos, N. F., Peres, C. A., and Cavalheiro, E. A. (1999). Effect of physical exercise on seizure occurrence in a model of temporal lobe epilepsy in rats. Epilepsy Res. 37, 45-52. doi: 10.1016/S0920-1211(99)00032-7

Austin, J. E., and Buckmaster, P. S. (2004). Recurrent excitation of granule cells with basal dendrites and low interneuron density and inhibitory postsynaptic current frequency in the dentate gyrus of macaque monkeys. J. Comp. Neurol. 476, 205-218. doi: 10.1002/cne.20182

Bonde, S., Ekdahl, C. T., and Lindvall, O. (2006). Long-term neuronal replacement in adult rat hippocampus after status epilepticus despite chronic inflammation. Eur. J. Neurosci. 23, 965-974. doi: 10.1111/j.1460-9568.2006. 04635.x 
Brown, J. P., Couillard-Després, S., Cooper-Kuhn, C. M., Winkler, J., Aigner, L., and Kuhn, H. G. (2003). Transient expression of doublecortin during adult neurogenesis. J. Comp. Neurol. 467, 1-10. doi: 10.1002/cne. 10874

Cao, F., Hata, R., Zhu, P., Ma, Y. J., Tanaka, J., Hanakawa, Y., et al. (2006). Overexpression of SOCS3 inhibits astrogliogenesis and promotes maintenance of neural stem cells. J. Neurochem. 98, 459-470. doi: 10.1111/j.1471-4159.2006.03890.x

Cavalheiro, E. A., Silva, D. F., Turski, W. A., Calderazzo-Filho, L. S., Bortolotto, Z. A., and Turski, L. (1987). The susceptibility of rats to pilocarpine-induced seizures is age-dependent. Dev. Brain Res. 37, 43-58. doi: 10.1016/0165-3806(87)90227-6

Cho, K. O., Lybrand, Z. R., Ito, N., Brulet, R., Tafacory, F., Zhang, L., et al. (2015). Aberrant hippocampal neurogenesis contributes to epilepsy and associated cognitive decline. Nat. Commun. 6:6606. doi: 10.1038/ncomms7606

Cotman, C. W., and Berchtold, N. C. (2002). Exercise: a behavioral intervention to enhance brain health and plasticity. Trends Neurosci. 25, 295-301. doi: 10.1016/S0166-2236(02)02143-4

Cotman, C. W., Berchtold, N. C., and Christie, L. A. (2007). Exercise builds brain health: key roles of growth factor cascades and inflammation. Trends Neurosci. 30, 464-472. doi: 10.1016/j.tins.2007.06.011

Couillard-Despres, S., Winner, B., Schaubeck, S., Aigner, R., Vroemen, M., Weidner, N., et al. (2005). Doublecortin expression levels in adult brain reflect neurogenesis. Eur. J. Neurosci. 21, 1-14. doi: 10.1111/j.1460-9568.2004.03813.x

Dashtipour, K., Wong, A. M., Obenaus, A., Spigelman, I., and Ribak, C. E. (2003). Temporal profile of hilar basal dendrite formation on dentate granule cells after status epilepticus. Epilepsy Res. 54, 141-151. doi: 10.1016/S0920-1211(03)00082-2

David, D. J., Samuels, B. A., Rainer, Q., Wang, J. W., Marsteller, D., Mendez, I., et al. (2009). Neurogenesis-dependent and-independent effects of fluoxetine in an animal model of anxiety/depression. Neuron 62, 479-493. doi: 10.1016/j.neuron.2009.04.017

de Lima, C., De Lira, C. A. B., Arida, R. M., Andersen, M. L., Matos, G., Guilhoto, L. M. D. F. F., et al. (2013). Association between leisure time, physical activity, and mood disorder levels in individuals with epilepsy. Physiol. Behav. 28, 47-51. doi: 10.1016/j.yebeh.2013.03.016

Denio, L. S., Drake, M. E. Jr., and Pakalnis, A. (1989). The effect of exercise on seizure frequency. J. Med. 20, 171-176.

Dishman, R. K., Armstrong, R. B., Delp, M. D., Graham, R. E., and Dunn, A. (1988). Open-field behavior is not related to treadmill performance in exercising rats. Physiol. Behav. 43, 541-546. doi: 10.1016/0031-9384(88) 90206-5

Drapeau, E., Mayo, W., Aurousseau, C., Le Moal, M., Piazza, P. V., and Abrous, D. N. (2003). Spatial memory performances of aged rats in the water maze predict levels of hippocampal neurogenesis. Proc Natl Acad Sci U.S.A. 100, 14385-14390. doi: 10.1073/pnas.2334169100

Drew, M. R., and Hen, R. (2007). Adult hippocampal neurogenesis as target for the treatment of depression. CNS Neurol. Disord. Drug Targets 6, 205-218. doi: 10.2174/187152707780619353

Duan, X., Kang, E., Liu, C. Y., Ming, G. L., and Song, H. (2008). Development of neural stem cell in the adult brain. Curr. Opin. Neurobiol. 18, 108-115. doi: 10.1016/j.conb.2008.04.001

Duncan, J. S., Sander, J. W., Sisodiya, S. M., and Walker, M. C. (2006). Adult epilepsy. Lancet 367, 1087-1100. doi: 10.1016/S0140-6736(06)68477-8

Eriksen, H. R., Grønningsaeter, H., Nakken, K. O., Løyning, Y., and Ursin, H. (1994). Physical exercise in women with intractable epilepsy. Epilepsia 35, 1256-1264. doi: 10.1111/j.1528-1157.1994.tb01797.x

Fabel, K., Fabel, K., Tam, B., Kaufer, D., Baiker, A., Simmons, N., et al. (2003). VEGF is necessary for exercise-induced adult hippocampal neurogenesis. Eur. J. Neurosci. 18, 2803-2812. doi: 10.1111/j.1460-9568.2003.03041.x

Fisher, R. S., Boas, W. V. E., Blume, W., Elger, C., Genton, P., Lee, P., et al. (2005). Epileptic seizures and epilepsy: definitions proposed by the International League Against Epilepsy (ILAE) and the International Bureau for Epilepsy (IBE). Epilepsia 46, 470-472. doi: 10.1111/j.0013-9580.2005.66104.x

Gage, F. H. (2000). Mammalian neural stem cells. Science 287, 1433-1438. doi: $10.1126 /$ science.287.5457.1433

Gobbo, O. L., and O'mara, S. M. (2005). Exercise, but not environmental enrichment, improves learning after kainic acid-induced hippocampal neurodegeneration in association with an increase in brainderived neurotrophic factor. Behav. Brain Res. 159, 21-26. doi: 10.1016/j.bbr.2004.09.021

Gomes, F. N., da Silva, S. G., Cavalheiro, E. A., and Arida, R. M. (2014). Beneficial influence of physical exercise following status epilepticus in the immature brain of rats. Neuroscience 274, 69-81. doi: 10.1016/j.neuroscience.2014. 05.024

Gómez-Pinilla, F., Dao, L., and So, V. (1997). Physical exercise induces FGF-2 and its mRNA in the hippocampus. Brain Res. 764, 1-8. doi: 10.1016/S0006-8993(97)00375-2

Hattiangady, B., Rao, M. S., and Shetty, A. K. (2004). Chronic temporal lobe epilepsy is associated with severely declined dentate neurogenesis in the adult hippocampus. Neurobiol. Dis. 17, 473-490. doi: 10.1016/j.nbd.2004.08.008

Hattiangady, B., and Shetty, A. K. (2008). Implications of decreased hippocampal neurogenesis in chronic temporal lobe epilepsy. Epilepsia 49, 26-41. doi: $10.1111 / j .1528-1167.2008 .01635 . x$

Hattiangady, B., and Shetty, A. K. (2010). Decreased neuronal differentiation of newly generated cells underlies reduced hippocampal neurogenesis in chronic temporal lobe epilepsy. Hippocampus 20, 97-112. doi: 10.1002/hipo.20594

Hester, M. S., and Danzer, S. C. (2013). Accumulation of abnormal adult-generated hippocampal granule cells predicts seizure frequency and severity. J. Neurosci. 33, 8926-8936. doi: 10.1523/JNEUROSCI.5161-12.2013

Intlekofer, K. A., and Cotman, C. W. (2013). Exercise counteracts declining hippocampal function in aging and Alzheimer's disease. Neurobiol. Dis. 57, 47-55. doi: 10.1016/j.nbd.2012.06.011

Jessberger, S., Nakashima, K., Clemenson, G. D., Mejia, E., Mathews, E., Ure, K., et al. (2007a). Epigenetic modulation of seizure-induced neurogenesis and cognitive decline. J. Neurosci. 27, 5967-5975. doi: 10.1523/JNEUROSCI.0110-07.2007

Jessberger, S., Zhao, C., Toni, N., Clemenson, G. D., Li, Y., and Gage, F. H. (2007b). Seizure-associated, aberrant neurogenesis in adult rats characterized with retrovirus-mediated cell labeling. J. Neurosci. 27, 9400-9407. doi: 10.1523/JNEUROSCI.2002-07.2007

Kim, S. H., Kim, H. B., Jang, M. H., Lim, B. V., Kim, Y. J., Kim, Y. P., et al. (2002). Treadmill exercise increases cell proliferation without altering of apoptosis in dentate gyrus of Sprague-Dawley rats. Life Sci. 71, 1331-1340. doi: 10.1016/S0024-3205(02)01849-0

Kuruba, R., Hattiangady, B., and Shetty, A. K. (2009). Hippocampal neurogenesis and neural stem cells in temporal lobe epilepsy. Epilepsy Behav. 14, 65-73. doi: 10.1016/j.yebeh.2008.08.020

Lee, M. C., Inoue, K., Okamoto, M., Liu, Y. F., Matsui, T., Yook, J. S., et al. (2013). Voluntary resistance running induces increased hippocampal neurogenesis in rats comparable to load-free running. Neurosci. Lett. 537, 6-10. doi: 10.1016/j.neulet.2013.01.005

Ma, D. K., Bonaguidi, M. A., Ming, G. L., and Song, H. (2009). Adult neural stem cells in the mammalian central nervous system. Cell Res. 19, 672-682. doi: $10.1038 /$ cr.2009.56

Malberg, J. E., Eisch, A. J., Nestler, E. J., and Duman, R. S. (2000). Chronic antidepressant treatment increases neurogenesis in adult rat hippocampus. $J$. Neurosci. 20, 9104-9110.

Manji, H. K., Drevets, W. C., and Charney, D. S. (2001). The cellular neurobiology of depression. Nat. Med. 7, 541-547. doi: 10.1038/87865

McAuley, J. W., Long, L., Heise, J., Kirby, T., Buckworth, J., Pitt, C., et al. (2001). A prospective evaluation of the effects of a 12-week outpatient exercise program on clinical and behavioral outcomes in patients with epilepsy. Epilepsy Behav. 2, 592-600. doi: 10.1006/ebeh.2001.0271

Ming, G. L., and Song, H. (2011). Adult neurogenesis in the mammalian brain: significant answers and significant questions. Neuron 70, 687-702. doi: 10.1016/j.neuron.2011.05.001

Nestler, E. J., Barrot, M., DiLeone, R. J., Eisch, A. J., Gold, S. J., and Monteggia, L. M. (2002). Neurobiology of depression. Neuron 34, 13-25. doi: 10.1016/S0896-6273(02)00653-0

Nokia, M. S., Lensu, S., Ahtiainen, J. P., Johansson, P. P., Koch, L. G., Britton, S. L., et al. (2016). Physical exercise increases adult hippocampal neurogenesis in male rats provided it is aerobic and sustained. J. Physiol. 594, 1855-1873. doi: 10.1113/JP271552

Olson, A. K., Eadie, B. D., Ernst, C., and Christie, B. R. (2006). Environmental enrichment and voluntary exercise massively increase neurogenesis in the 
adult hippocampus via dissociable pathways. Hippocampus 16, 250-260. doi: 10.1002/hipo.20157

Parent, J. M. (2007). Adult neurogenesis in the intact and epileptic dentate gyrus. Prog. Brain Res. 163, 529-540. doi: 10.1016/S0079-6123(07)63028-3

Parent, J. M., Elliott, R. C., Pleasure, S. J., Barbaro, N. M., and Lowenstein, D. H. (2006). Aberrant seizure-induced neurogenesis in experimental temporal lobe epilepsy. Ann Neurol. 59, 81-91. doi: 10.1002/ana.20699

Parent, J. M., and Lowenstein, D. H. (2002). Seizure-induced neurogenesis: are more new neurons good for an adult brain? Prog. Brain Res. 135, 121-131. doi: 10.1016/S0079-6123(02)35012-X

Parent, J. M., Timothy, W. Y., Leibowitz, R. T., Geschwind, D. H., Sloviter, R. S., and Lowenstein, D. H. (1997). Dentate granule cell neurogenesis is increased by seizures and contributes to aberrant network reorganization in the adult rat hippocampus. J. Neurosci. 17, 3727-3738.

Paxinos, G., and Watson, C. (2007). The Rat Brain in Stereotaxic Coordinates, 6th Edn. San Diego, CA: Elsevier Academic Press.

Ribak, C. E., Tran, P. H., Spigelman, I., Okazaki, M. M., and Nadler, J. V. (2000). Status epilepticus-induced hilar basal dendrites on rodent granule cells contribute to recurrent excitatory circuitry. J. Comp. Neurol. 428, 240-253. doi: 10.1002/1096-9861(20001211)428:2<240::AID-CNE4>3.0.CO;2-Q

Roth, D. L., Goode, K. T., Williams, V. L., and Faught, E. (1994). Physical exercise, stressful life experience, and depression in adults with epilepsy. Epilepsia 35, 1248-1255. doi: 10.1111/j.1528-1157.1994.tb01796.x

Russo-Neustadt, A. A., Alejandre, H., Garcia, C., Ivy, A. S., and Chen, M. J. (2004). Hippocampal brain-derived neurotrophic factor expression following treatment with reboxetine, citalopram, and physical exercise. Neuropsychopharmacology 29, 2189-2199. doi: 10.1038/sj.npp.1300514

Sahay, A., and Hen, R. (2007). Adult hippocampal neurogenesis in depression. Nat. Neurosci. 10, 1110-1115. doi: 10.1038/nn1969

Santarelli, L., Saxe, M., Gross, C., Surget, A., Battaglia, F., Dulawa, S., et al. (2003). Requirement of hippocampal neurogenesis for the behavioral effects of antidepressants. Science 301, 805-809. doi: 10.1126/science.1083328

Scharfman, H. E., Goodman, J. H., and Sollas, A. L. (2000). Granule-like neurons at the hilar/CA3 border after status epilepticus and their synchrony with area CA3 pyramidal cells: functional implications of seizureinduced neurogenesis. J. Neurosci. 20, 6144-6158.

Scharfman, H. E., and Pierce, J. P. (2012). New insights into the role of hilar ectopic granule cells in the dentate gyrus based on quantitative anatomic analysis and three-dimensional reconstruction. Epilepsia 53, 109-115. doi: 10.1111/j.1528-1167.2012.03480.x

Scharfman, H. E., Sollas, A. E., Berger, R. E., Goodman, J. H., and Pierce, J. P. (2003). Perforant path activation of ectopic granule cells that are born after pilocarpine-induced seizures. Neuroscience 121, 1017-1029. doi: 10.1016/S0306-4522(03)00481-0

Scharfman, H. E., Sollas, A. L., Smith, K. L., Jackson, M. B., and Goodman, J. H. (2002). Structural and functional asymmetry in the normal and epileptic rat dentate gyrus. J. Comp. Neurol. 454, 424-439. doi: 10.1002/cne.10449

Shapiro, L. A., and Ribak, C. E. (2006). Newly born dentate granule neurons after pilocarpine-induced epilepsy have hilar basal dendrites with immature synapses. Epilepsy Res. 69, 53-66. doi: 10.1016/j.eplepsyres.2005.12.003

Shetty, A. K., Zaman, V., and Shetty, G. A. (2003). Hippocampal neurotrophin levels in a kainate model of temporal lobe epilepsy: a lack of correlation between brain-derived neurotrophic factor content and progression of aberrant dentate mossy fiber sprouting. J. Neurochem. 87, 147-159. doi: 10.1046/j.1471-4159.2003.01979.x
Shors, T. J., Townsend, D. A., Zhao, M., Kozorovitskiy, Y., and Gould, E. (2002). Neurogenesis may relate to some but not all types of hippocampal-dependent learning. Hippocampus 12, 578-584. doi: 10.1002/hipo.10103

Steiner, B., Kronenberg, G., Jessberger, S., Brandt, M. D., Reuter, K., and Kempermann, G. (2004). Differential regulation of gliogenesis in the context of adult hippocampal neurogenesis in mice. Glia 46, 41-52. doi: 10.1002/glia.10337

Thind, K. K., Ribak, C. E., and Buckmaster, P. S. (2008). Synaptic input to dentate granule cell basal dendrites in a rat model of temporal lobe epilepsy. J. Comp. Neurol. 509, 190-202. doi: 10.1002/cne.21745

Uda, M., Ishido, M., Kami, K., and Masuhara, M. (2006). Effects of chronic treadmill running on neurogenesis in the dentate gyrus of the hippocampus of adult rat. Brain Res. 1104, 64-72. doi: 10.1016/j.brainres.2006.05.066

van der Borght, K., Kóbor-Nyakas, D. É., Klauke, K., Eggen, B. J., Nyakas, C., Van der Zee, E. A., et al. (2009). Physical exercise leads to rapid adaptations in hippocampal vasculature: temporal dynamics and relationship to cell proliferation and neurogenesis. Hippocampus 19, 928-936. doi: 10.1002/hipo.20545

van Praag, H. (2008). Neurogenesis and exercise: past and future directions. Neuromol. Med. 10, 128-140. doi: 10.1007/s12017-0088028-z

van Praag, H., Christie, B. R., Sejnowski, T. J., and Gage, F. H. (1999). Running enhances neurogenesis, learning, and long-term potentiation in mice. Proc. Natl. Acad. Sci. U.S.A. 96, 13427-13431. doi: 10.1073/pnas.96.23.13427

van Praag, H., Schinder, A. F., Christie, B. R., Toni, N., Palmer, T. D., and Gage, F. H. (2002). Functional neurogenesis in the adult hippocampus. Nature 415, 1030-1034. doi: 10.1038/4151030a

Vaynman, S., and Gomez-Pinilla, F. (2005). License to run: exercise impacts functional plasticity in the intact and injured central nervous system by using neurotrophins. Neurorehabil. Neural Repair. 19, 283-295. doi: $10.1177 / 1545968305280753$

Vaynman, S., Ying, Z., and Gomez-Pinilla, F. (2004). Hippocampal BDNF mediates the efficacy of exercise on synaptic plasticity and cognition. Eur. J. Neurosci. 20, 2580-2590. doi: 10.1111/j.1460-9568.2004.03720.x

Walter, C., Murphy, B. L., Pun, R. Y., Spieles-Engemann, A. L., and Danzer, S. C. (2007). Pilocarpine-induced seizures cause selective time-dependent changes to adult-generated hippocampal dentate granule cells. J. Neurosci. 27, 7541-7552. doi: 10.1523/JNEUROSCI.0431-07.2007

Wojtowicz, J. M., and Kee, N. (2006). BrdU assay for neurogenesis in rodents. Nat. Protoc. 1, 1399-1405. doi: 10.1038/nprot.2006.224

Zhao, C., Deng, W., and Gage, F. H. (2008). Mechanisms and functional implications of adult neurogenesis. Cell 132, 645-660. doi: 10.1016/j.cell.2008.01.033

Conflict of Interest Statement: The authors declare that the research was conducted in the absence of any commercial or financial relationships that could be construed as a potential conflict of interest.

Copyright (c) 2017 Mendonça, Santos, Rodrigues, Gomes da Silva, Arida, da Silveira, Scorza and Almeida. This is an open-access article distributed under the terms of the Creative Commons Attribution License (CC BY). The use, distribution or reproduction in other forums is permitted, provided the original author(s) or licensor are credited and that the original publication in this journal is cited, in accordance with accepted academic practice. No use, distribution or reproduction is permitted which does not comply with these terms. 